\title{
Polyrotaxanes as emerging biomaterials for tissue engineering applications: a brief review
}

\author{
Arun Kumar Rajendan ${ }^{1}$, Yoshinori Arisaka², Nobuhiko Yui ${ }^{2}$ and Sachiko Iseki ${ }^{*}$
}

\begin{abstract}
The field of tissue engineering and regeneration constantly explores the possibility of utilizing various biomaterials' properties to achieve effective and uneventful tissue repairs. Polyrotaxanes (PRXs) are supramolecular assemblies, which possess interesting mechanical property at a molecular scale termed as molecular mobility. This molecular mobility could be utilized to stimulate various cellular mechanosignaling elements, thereby altering the cellular functions. Apart from this, the versatile nature of PRXs such as the ability to form complex with growth factors and peptides, numerous sites for chemical modifications, and processability into different forms makes them interesting candidates for applications towards tissue engineering. This literature briefly reviews the concepts of PRXs and molecular mobility, the versatile nature of PRXs, and its emerging utility towards certain tissue engineering applications.
\end{abstract}

\section{Background}

The search and designing of new biomaterials that can impart unique bio-interface functions and cellular modulations are never ending $[1,2]$. It has been shown that various mechanical properties of the biomaterial interfaces can be utilized to modulate different cellular responses [3-5]. Some of the biomaterial features that could initiate cellular mechanosignaling include the elasticity of the materials, stiffness, hardness, and topographical features such as groves, micro/nanopillars, geometry, and shape of cellular adhesion surfaces [6-9]. Furthermore, it has also been shown that the application of forces, either in static or cyclic form, in certain directions can bring about various changes in the cellular response and functions $[10,11]$. These mechanosignaling factors have been extensively studied and utilized in various biomaterial scaffolds for the purpose of tissue regeneration. One of the recent approaches is exploring

\footnotetext{
* Correspondence: s.iseki.emb@tmd.ac.jp

'Section of Molecular Craniofacial Embryology, Graduate School of Medical and Dental Sciences, Tokyo Medical and Dental University, 1-5-45 Yushima, Bunkyo-ku, Tokyo 113-8549, Japan

Full list of author information is available at the end of the article
}

the relative movement of molecules to one another, termed as molecular mobility, for modulating various cellular functions [12-14]. Molecular mobility is termed as the movement of certain molecules in relation to other molecules such as hinged flexing movement, sliding or rotation of ring-shaped molecule along an axle molecule, and many more [15]. Polyrotaxanes (PRXs) are one of the molecular assemblies which can exhibit molecular mobility.

\section{Polyrotaxanes and molecular mobility}

Polyrotaxanes are molecular assemblies resembling a beaded-chain but at molecular scales [16, 17] (Fig. 1). The chain component is usually made from long chain polymers such as poly(ethylene glycol) (PEG) and poly(propylene glycol) (PPG). This acts as the axle component for the molecular assembly on which the ring molecules can exhibit various motions. Some of the ring or bead molecules used to synthesize PRXs are cyclodextrins $(\mathrm{CD})$, crown ethers, or metal coordination complexes $[16,18]$. However, the most commonly used PRXs for biological application are based on PEG-CD supramolecular assemblies, as both of these components

(c) The Author(s). 2020 Open Access This article is licensed under a Creative Commons Attribution 4.0 International License, which permits use, sharing, adaptation, distribution and reproduction in any medium or format, as long as you give appropriate credit to the original author(s) and the source, provide a link to the Creative Commons licence, and indicate if changes were made. The images or other third party material in this article are included in the article's Creative Commons licence, unless indicated otherwise in a credit line to the material. If material is not included in the article's Creative Commons licence and your intended use is not permitted by statutory regulation or exceeds the permitted use, you will need to obtain permission directly from the copyright holder. To view a copy of this licence, visit http://creativecommons.org/licenses/by/4.0/. 


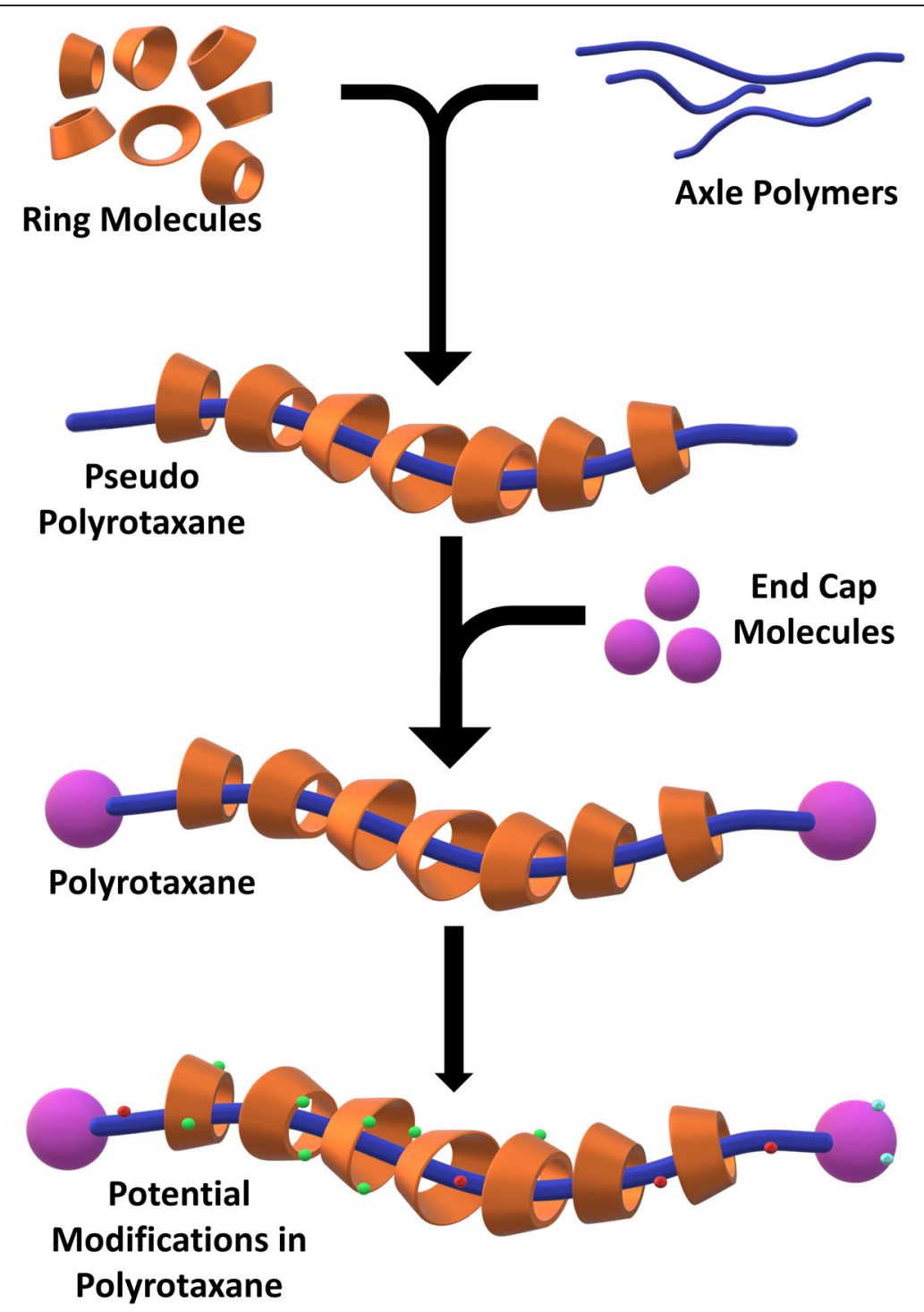

Fig. 1 One of the schematic of synthesis of the PRX supramolecular assembly. The long axle polymers (blue) are threaded into the ring-shaped molecules (orange) to form the pseudo PRX molecules. Then, end cap molecules (purple) are added to prevent the dethreading of ring molecules, thereby resulting in PRXs. This PRX can be further modified at various sites (green, red, cyan) to impart desirable functionalities according to the application

are well-known biocompatible and biodegradable materials. The CDs are threaded onto the PEG chain in aqueous environment after which bulky end groups are added to prevent the coming out of CDs. The complexation of CDs with PEG is governed by van der Waals forces between CDs and PEG as well as intermolecular hydrogen bonds of CDs. The mobility of CDs along the PEG chain is expected after diminishing the hydrogen bonds by chemical modifications such as methylation. The CD rings can shuttle along the PEG chain based upon hydration or other stimuli. The extent of shuttling of the $C D$ rings can be controlled by the number of $C D$ per PEG chain, thereby controlling the molecular mobility. In such architecture, the molecular mobility is inversely correlated with the number of CD/PEG chain, i.e., lesser the number of CDs per PEG, the CD rings can move extensively resulting in high molecular mobility. However, when more numbers of $\mathrm{CDs}$ are threaded onto a PEG chain, the space for the movement of CDs is restricted leading to low molecular mobility [19]. This molecular mobility or the mobility factor has been quantified using methods such as wet and dry contact angle measurements and quartz crystal microbalance dissipation (QCM-D) studies [20, 21]. Furthermore, some researchers have shown that these $\mathrm{CD}$ rings can also be crosslinked to act like pulleys for the polymeric chains, which leads to the formation of very highly stretchable biomaterials [22]. Further, the CDs or the 
axle polymeric chains can accept numerous chemical modifications and conjugation of peptides, vitamins, or carbohydrates, which paves the way for the wide field of applications [23-26]. This brief review will cover the PRXs made from the CD-PEG complexes as these are the most widely explored towards biomaterial applications.

\section{Versatility of PRXs}

PRXs are complex supramolecular assemblies which allow us the ability to modify several parameters such as the choice of axle polymer, molecular weight of the axle polymer, the number of CDs per polymer chain, addition of side chains to the axle polymer, modification of the $C D$ with functional groups, addition of side chains to the CDs, and/or conjugation of peptides to the CDs [27, 28]. The presence of multivalency and molecular mobility in PRX supramolecular assemblies is also one of the key mechanisms which leads to improved efficiency of cell-ligand interactions [23-25]. Some of the commonly used polymers for the axle include but not restricted to PEG, PPG, poly(dimethylsiloxane), poly( $\varepsilon$-lysine), poly( $\varepsilon$-caprolactone) (PCL), poly(L-lactic acid), and nylon. CDs can be composed of six, seven, or eight glycosyl units, and they are named as $\alpha-C D, \beta-C D$, and $\gamma-C D$ respectively. The choice of determining the suitable axle polymer and the type of $\mathrm{CD}$ usually depends on the cavity diameter of the $\mathrm{CD}$. For example, PEG, PCL, and poly(adipate)-based PRXs can be formed by complexing with $\alpha$ - and $\gamma$-CD only; however, when PPG or poly(1,3-dioxolane) is chosen as the axle polymer, all three forms of CDs can be threaded [29].

PRXs can be processed into scaffolds with controllable pore sizes. This helps to widen the utility for tissue engineering applications. PEG hydrogel scaffolds were produced by crosslinking hydrolyzable PRXs and also with cholesterol functionalized PRXs which were explored for cartilage regenerative applications. Hydrolyzable PRXscaffolds containing hydroxyapatite particles were also synthesized and were suggested to exhibit promising outcomes for bone tissue engineering. PRXs can be utilized as crosslinkers for the poly( $N$-isopropylacrylamide) (PIPAAm) polymeric networks, thereby yielding a thermoresponsive and extremely stretchable hydrogel, which could be used for muscle tissue engineering [22, 30]. Similar high elastic hydrogels can be prepared by crosslinking acrylate monomers with slide-ring PRXs by exploiting the pulley effect [31]. Self-healing hydrogels can also be synthesized by creating a reversible bond between the ring molecules of PRXs and poly (acrylamide) [32]. Various stimuli-responsive PRX hydrogels, such as $\mathrm{pH}$-sensitive, thermo-sensitive, photo-sensitive, etc., have been synthesized which could be potentially used for the on-demand delivery of drugs, peptides, or genes. These are usually synthesized by adjusting the threading CDs and the length of the polymeric axle, making chemical substitutions in the PRXs or by introducing stimulisensitive groups, which either breaks down or changes the conformation upon the necessary stimuli [33, 34]. For example, self-assembled PRX particles with disulfide bonds that could degrade and release the encapsulated drugs in the reducing environment have been developed [35]. Azo-substituted PRXs with PIPAAm exhibited responses to heat and UV stimuli [36]. Improving upon this, by introducing both a photo-initiator molecule and a photolabile group into the PRX crosslinker-based resin, it was shown that, upon exposure to 450-nm light, the PRX-based resin hardened, but when the hardened resin was irradiated with $250-300 \mathrm{~nm}$ UV light, the tensile strength of the resin reduced significantly indicating the photolabile nature [37]. Apart from these, functional group modifications such as acetylation, methoxylation or sulfonation, and conjugation of PRXs with peptides such as RGD, BMP2, and FGF2 have also been carried out on PRXs in order to improve cellular interactions [38-40]. With such numerous options to modify, improve, and incorporate unique features, PRXs can be considered to be one of the very versatile biomaterials allowing us to cater a wide array of clinical requirements.

\section{PRXs in directing stem cell commitment}

Controlling the commitment of stem cells has a lot of implications in the field of tissue engineering and regenerative medicine. Growth factors, chemical supplements, siRNAs, and a combination of these have been studied extensively for the purpose of directing stem cell commitment [41-43]. It has been well established that the fate of stem cell differentiation also depends on the mechanical cues from the microenvironment [44]. Taking insights from this fact, PRXs with different molecular mobilities have been synthesized and their potential to alter the fate of stem cells were explored. Seo et al. explored the possibility of directing the MSCs into osteoblastic and adipocytic lineages by seeding them onto PRXs with low or high molecular mobilities, respectively [45]. It was found that molecular mobility influences the cellular response through focal adhesion kinases, actin organization, and RhoA-ROCK mechanosignaling pathway. On a high mobile PRX surface, the RhoA-ROCK signaling was inhibited, thereby directing the MSCs to enter into adipogenic differentiation; however, when the RhoA-ROCK was activated on the low mobile PRX surface, the MSCs differentiated into osteoblasts. Thereby, the possibility of using thin coatings of PRXs with different molecular mobility on the materials-surface to alter the stem cell commitment was established.

Extending upon this work, the effect of PRX molecular mobility was studied in the context of inducing cardiomyocytes from mouse iPS cells (iPSCs). Culturing iPSCs 
on PRXs with high mobility lead to the higher expression of Rac1 and $\mathrm{N}$-cadherin expression indicating the strong cell-cell interactions when compared to cells cultured on gelatin-coated surfaces. The number of beating colonies indicating the successful cardiomyogenic commitment was higher on the high mobile PRX surface. Furthermore, the cardiomyocyte genes such as $\alpha-\mathrm{MHC}$, TnT2, and HCN4 were highly expressed in iPSCs cultured on high mobile PRXs confirming that PRX surface with high mobility could be effectively utilized to induce cardiomyocyte commitment from iPSCs [46].

Recently, it was reported that molecular mobility of PRXs could alter the stemness and differentiation capability of bone marrow-derived MSCs even during a short culture span [47]. It was found that immobilization of bFGF to sulfonated PRXs (S-PRXs) helped to increase the yield of MSCs and the molecular mobility played a major role in retaining the stemness of these cells. The MSCs cultured over high mobile S-PRX surfaces exhibited poor actin organization, retention of a key mechanosignaling element of YAP in the cytoplasm, and higher levels of stemness marker gene expression such as Nanog and Oct4. Further, when these MSCs were collected and replated onto regular tissue culture polystyrene plates, only the cells grown on high mobile S-PRX surfaces with bFGF were able to differentiate into osteoblasts.

\section{PRXs in enhancing osteogenic differentiation}

Biomaterials for bone tissue engineering and enhancing osteogenic differentiation are of great importance as bone is the most widely transplanted tissue next to blood transfusions [48]. Although autografts remain as the gold standard for bone tissue repair, bone graft substitutes and alternative solutions to enhance the regenerative capacity of bone tissues are persistently being sought upon, owing to the practical limitations of autografts [49]. The molecular mobility and the ability of PRXs to be modified with various functional groups and complex with growth factors have been explored for the purpose of enhancing bone regeneration. Bone morphogenetic protein 2 (BMP2) was complexed with S-PRXs and its efficacy in osteogenic differentiation was evaluated [50]. A polyelectrolytic complex of S-PRX and BMP2 was synthesized by combining negatively charged S-PRXs with positively charged BMP2. Sulfonation of CDs in the S-PRX helps to enhance the activity of BMP2, mimicking the function of heparin, proving to be advantageous than heparin to be used in a clinical scenario since S-PRXs did not exhibit the anticoagulant activity. It was found that S-PRX/BMP2 complex significantly increased the osteogenic activity of MC3T3E1 cells when compared to free BMP2 and heparinBMP2 complex. The enhancement of osteogenic activity was due to S-PRX/BMP2 complex enhancing the tolerability to noggin-induced deactivation and also prolonging the Smad signaling. Further, these complexes were shown to significantly improve the bone regeneration in vivo, when it was encapsulated within collagen sponges and implanted into the mouse calvarial defects [51]. Extending upon this, it was shown that it is possible to immobilize BMP-2 onto the previously dried surface coating of S-PRXs. This possibly allows PRX to be stored for a longer duration and immobilization of BMP2 can be done a few hours before the clinical application. The osteogenic differentiation of MC3T3-E1 cells was enhanced on the BMP2-immobilized S-PRX surface compared to free soluble form of BMP2 [52].

\section{PRXs for cartilage regeneration}

Cartilage regenerative therapies mainly focus on finding suitable biomaterial scaffolds to support the growth of chondrocytes and aid the secretion of extracellular matrix proteins in a spatiotemporally controlled pattern for matching the native healthy tissue as close as possible [53]. Lee et al. synthesized a porous hydrogel which consists of PEG crosslinked with hydrolyzable PRX [54]. The scaffold showed promising results for the proliferation of the chondrocytes in vitro. Further, the microporous hydrogel scaffold was able to trap a higher number of chondrocytes due to the primary amine functionalization in the PRXs [55]. The erosion rate of the PRXbased hydrogel scaffold was also controllable, thereby providing ample time for the chondrocytes to produce of glycosaminoglycan (GAG), indicative of promising use in cartilage regeneration. A similar hydrogel scaffold was synthesized by introducing cholesterol moieties in the PRXs, which has the advantage to mimic the lipid layers in the cell membrane, thereby improving the biocompatibility [56]. It also helped to control the Young's modulus and the rate of degradation of the PRXscaffold. It was found that the GAG content increased with the addition of cholesterol groups up to $15 \%$ degree of substitution. With the ability to retain huge amounts of water, form interconnected porous structures, and tune the mechanical properties such as the Young's modulus and the degradation rates, PRX-based scaffolds are interesting candidates for cartilage regeneration.

\section{PRXs for other tissue engineering applications}

Cellular adhesion is one of the most important requirements for biomaterial interfaces in the tissue engineering approach. It has been found that the molecular mobility of PRXs could be used to alter the cellular adhesion patterns. Generally, PRXs with low mobility tend to enhance the cellular adhesion and spreading of adherent cells such as fibroblasts, MC3T3-E1, and MSCs [47]. This could be because the low mobile PRX could mimic 
Table 1 List of a few of the different modifications of PRX, the various processability of PRXs, and the effect of molecular mobility on cellular functions and their possible applications

\begin{tabular}{|c|c|c|c|c|c|c|}
\hline No. & Type of PRX & Usage form & Type of study & Notable finding $^{1}$ & Possible application & Reference \\
\hline 1 & Methylated PRX & Thin coating & In vitro; hMSC & $\begin{array}{l}\text { H.Mf: } \downarrow \text { RhoA signaling; L.Mf: } \uparrow \\
\text { RhoA signaling }\end{array}$ & $\begin{array}{l}\text { Modulating stem cell } \\
\text { differentiation into } \\
\text { adipogenic or osteogenic }\end{array}$ & [45] \\
\hline 2 & Methylated PRX & Thin coating & In vitro; iPSC & $\begin{array}{l}\text { H.Mf: } \uparrow \operatorname{Rac1}, \uparrow T n T 2 ; \text { L.Mf: } \\
\text { Rac1, } \downarrow T n T 2\end{array}$ & $\begin{array}{l}\text { Enhancing cardiomyocyte } \\
\text { differentiation from iPSCs }\end{array}$ & [46] \\
\hline 3 & $\begin{array}{l}\text { bFGF immobilized } \\
\text { S-PRX }\end{array}$ & Thin coating & In vitro; hMSC & $\begin{array}{l}\text { H.Mf: } \uparrow \text { Nanog, } \uparrow \text { Oct4, } \\
\text { Cytoplasmic YAP; L.Mf: } \downarrow \\
\text { Nanog, } \downarrow \text { Oct4, Nuclear YAP }\end{array}$ & $\begin{array}{l}\text { Retention of hMSCs } \\
\text { stemness during expansion } \\
\text { phase }\end{array}$ & [47] \\
\hline 4 & BMP2/S-PRX & $\begin{array}{l}\text { Polyelectrolyte } \\
\text { complex }\end{array}$ & In vitro; MC3T3-E1 & $\begin{array}{l}\text { More tolerant to noggin } \\
\text { deactivation, prolonged } \\
\text { Smad signaling }\end{array}$ & $\begin{array}{l}\text { Enhancing osteogenic } \\
\text { differentiation }\end{array}$ & {$[50]$} \\
\hline 5 & BMP2/S-PRX & $\begin{array}{l}\text { Polyelectrolyte } \\
\text { complex coated } \\
\text { onto collagen } \\
\text { scaffold }\end{array}$ & $\begin{array}{l}\text { In Vivo; mouse } \\
\text { cranial defect }\end{array}$ & Rapid bone regeneration & Potential bone graft substitute & [51] \\
\hline 6 & BMP2 tethered S-PRX & Thin coating & In vitro; MC3T3-E1 & $\begin{array}{l}\text { Tethering BMP2 to S-PRX } \\
\text { enhances cell adhesion and } \\
\text { osteogenic gene expression }\end{array}$ & $\begin{array}{l}\text { Enhancing osteogenic } \\
\text { differentiation }\end{array}$ & [52] \\
\hline 7 & $\begin{array}{l}\text { PEG crosslinked with } \\
\text { aminated PRX }\end{array}$ & Porous scaffold & $\begin{array}{l}\text { In vitro; primary } \\
\text { rabbit chondrocytes }\end{array}$ & $\begin{array}{l}\text { Interconnected pores in } \\
\text { scaffold; fast water absorption } \\
\text { and swelling of hydrogel; very } \\
\text { good cell adhesion }\end{array}$ & $\begin{array}{l}\text { Potential scaffold for cartilage } \\
\text { regeneration }\end{array}$ & [54] \\
\hline 8 & $\begin{array}{l}\text { PEG crosslinked with } \\
\text { aminated PRX and } \\
\text { terminal ester linkages }\end{array}$ & Porous scaffold & $\begin{array}{l}\text { In vitro; primary } \\
\text { rabbit chondrocytes }\end{array}$ & $\begin{array}{l}\text { Enhanced trapping of cells; } \\
\text { tunable degradation of } \\
\text { scaffold; enhanced GAG } \\
\text { production }\end{array}$ & $\begin{array}{l}\text { Potential scaffold for cartilage } \\
\text { regeneration }\end{array}$ & [55] \\
\hline 9 & $\begin{array}{l}\text { Cholesterol-modified } \\
\text { PRX }\end{array}$ & Porous scaffold & $\begin{array}{l}\text { In vitro; primary } \\
\text { rabbit chondrocytes }\end{array}$ & $\begin{array}{l}\text { Enhanced cell adhesion; } \\
\text { tunable degradation of } \\
\text { scaffold; enhanced GAG } \\
\text { production }\end{array}$ & $\begin{array}{l}\text { Potential scaffold for cartilage } \\
\text { regeneration }\end{array}$ & {$[56]$} \\
\hline 10 & RGD-conjugated PRX & $\begin{array}{l}\text { Injectable } \\
\text { scaffold }\end{array}$ & $\begin{array}{l}\text { In vitro; L929 mouse } \\
\text { fibroblasts }\end{array}$ & $\begin{array}{l}\text { Enhanced biocomaptibility } \\
\text { and cell adhesion }\end{array}$ & Injectable hydrogel scaffold & [58] \\
\hline 11 & RGD-conjugated PRX & Thin coating & In vitro; NIH3T3 & $\begin{array}{l}\text { Rapid integrin binding; } \\
\text { more cellular spreading }\end{array}$ & $\begin{array}{l}\text { Improving ligand-cell } \\
\text { interaction in biomaterial } \\
\text { surfaces }\end{array}$ & [38] \\
\hline 12 & $\begin{array}{l}\text { VEGF-immobilized } \\
\text { S-PRX }\end{array}$ & Thin coating & In vitro; HUVEC & $\begin{array}{l}\text { L.Mf: enhanced cell } \\
\text { proliferation; increased RhoA, } \\
\text { Pdgf, ang1; increased } \\
\text { endothelial network }\end{array}$ & Enhancing angiogenesis & {$[60]$} \\
\hline 13 & $\begin{array}{l}\text { HBEGF-immobilized } \\
\text { S-PRX }\end{array}$ & Thin coating & In vitro; HEPG2 & $\begin{array}{l}\text { H.Mf: cytoplasmic YAP } \\
\text { retention; increased albumin } \\
\text { secretion }\end{array}$ & $\begin{array}{l}\text { Proliferating functional } \\
\text { hepatic cells; liver tissue } \\
\text { engineering }\end{array}$ & [61] \\
\hline 14 & RGD-conjugated PRX & Thin coating & In vitro; PC12 & Increased cellular adhesion & $\begin{array}{l}\text { Modulating neuronal } \\
\text { differentiation }\end{array}$ & [63] \\
\hline 15 & RGD-conjugated PRX & Thin coating & In vitro; P19CL6 & $\begin{array}{l}\text { Early formation of beating } \\
\text { cardiomyocytes }\end{array}$ & $\begin{array}{l}\text { Modulating cardiomyocyte } \\
\text { differentiation }\end{array}$ & [63] \\
\hline 16 & Methylated PRX & Thin Coating & In vitro; C2C12 & $\begin{array}{l}\text { Enhanced myogenesis } \\
\text { related genes }\end{array}$ & Muscle regeneration & [64] \\
\hline 17 & $\begin{array}{l}\text { PRX-crosslinked } \\
\text { collagen }\end{array}$ & $\begin{array}{l}\text { Corneal } \\
\text { membrane }\end{array}$ & $\begin{array}{l}\text { In vivo; rabbit } \\
\text { corneal injury }\end{array}$ & $\begin{array}{l}\text { Enhanced remodeling of } \\
\text { corneal epithelium and } \\
\text { stroma }\end{array}$ & Corneal regeneration & [65] \\
\hline 18 & Methylated PRX & Thin Coating & $\begin{array}{l}\text { In vivo, rat } \\
\text { subcutaneous } \\
\text { implantation }\end{array}$ & $\begin{array}{l}\text { H.Mf: induced collagen } \\
\text { fibrillogenesis; suppressed } \\
\text { recruitment of the } \\
\text { macrophage }\end{array}$ & $\begin{array}{l}\text { Collagen fibrillogenesis and } \\
\text { inflammation control }\end{array}$ & [62] \\
\hline
\end{tabular}


the mechanics of the native matrices of adherent cells leading to higher cell-biomaterial interactions. It could also be reasoned that due to excessive sliding of CDs in the high mobile PRXs, the cells may not achieve enough tractions for effective spreading seen on soft hydrogels, thereby inhibiting the other functions such as cell migration or proliferation [57]. Apart from utilizing the low molecular mobility of PRXs to enhance cellular adhesion, RGD peptides have also been conjugated to the dynamic CDs in the PRXs to synthesize cell adhesive hydrogel scaffold [58]. Seo et al. observed that the interaction with integrin was quicker and the cells exhibited larger initial adhesion area compared to RGD tethered onto non dynamic polymer $[38,39]$.

Formation of microvascular networks in implanted biomaterials is one of the key events for a successful tissue regeneration, as these microvessels are necessary for the efficient transport of cells, nutrients, and removal of the wastes [59]. It was observed that the molecular mobility of PRXs could be used to modulate the formation of microvascular networks [60]. Human umbilical vein endothelial cells (HUVECs) were cultured on VEGFimmobilized S-PRX surfaces, and they respond to different molecular mobility was studied. It was noted that low molecular mobility and VEGF immobilization enhanced the proliferation of HUVECs. The expression of genes required for endothelial network formation and angiogenesis, such as rhoA, pdgf, ang- 1 , and pecam-1, was increased in HUVECs cultured on low molecular mobile S-PRX surfaces with immobilized VEGF. This surface was also found to increase the number of endothelial networks formed in 5 days of HUVEC culture.

The effect of molecular mobility of S-PRXs on hepatocyte functions has also been explored by using HepG2 cells [61]. Heparin-binding epidermal growth factor-like growth factor (HB-EGF) was immobilized onto the SPRX surfaces. The high mobile S-PRX surface showed retention of YAP in the cytoplasm which is required for the optimal proliferation, survival, and maintenance of hepatic functions, compared to the nuclear YAP localization in the low mobile S-PRX surface. Consistently, the albumin secretion, one of the key hepatic functions, was significantly higher in the cells cultured on high mobile S-PRX with immobilized HB-EGF, indicating that these surfaces could be useful in hepatocyte cultures and liver tissue engineering applications.

The molecular mobility of polyrotaxane surfaces also affected collagen fibrillogenesis. Although the extent of molecular mobility was independent of the absorbing amount of collagen, higher mobility of polyrotaxane surfaces preferentially induced rearrangement of adsorbed collagen and caused collagen fibrillogenesis. When PRXcoated substrates were implanted subcutaneously in rats, it was observed that the recruitment of macrophages at the implant site was suppressed by polyrotaxane surfaces with higher mobility. These results suggest that the molecular mobility of polyrotaxane helps suppress inflammation and promote regeneration in vivo [62].

\section{Conclusions and future directions}

As briefly reviewed above, we could see that PRXs are a novel class of supramolecular assemblies which exhibit mechanical movements at a molecular scale. It has also been shown that these mechanical signals from the molecular mobility of PRXs could be harnessed and utilized for modulating various mechanosignaling pathways and thereby driving specific gene expressions (Table 1). One of the peculiar advantages of PRXs is that the effects of molecular mobility holds true at various scales, such as hydrogels, scaffolds, and even in thin coatings. This allows us to utilize PRXs in various forms for different clinical scenarios. Furthermore, with the other advantages of being able to synthesize from biocompatible and biodegradable precursors and the ability to add various chemical groups, peptides, growth factors, and vitamins to impart cell-specific functions in the field of tissue engineering in the future, it should also be noted that different types of cell or tissues could exhibit different responses even to the same kind of PRXs. Therefore, it is necessary to design and choose the appropriate type of PRXs for a specific application. However, it could also be foreseen that researchers might develop multilayered or multiscale constructs in which different segments of the construct could exhibit different molecular mobility, thereby closely mimicking the complex layers and mechanics of the real tissues. However, we could see that most of the studies have shown the intended effects of PRXs only in the in vitro stage, except for a handful of studies in vivo. Exploring the in vivo effects could possibly bring the interesting potentials of PRXs to the clinical benches. Thus, PRX-based biomaterials hold promising directions in the field of mechanobiology mediated tissue engineering.

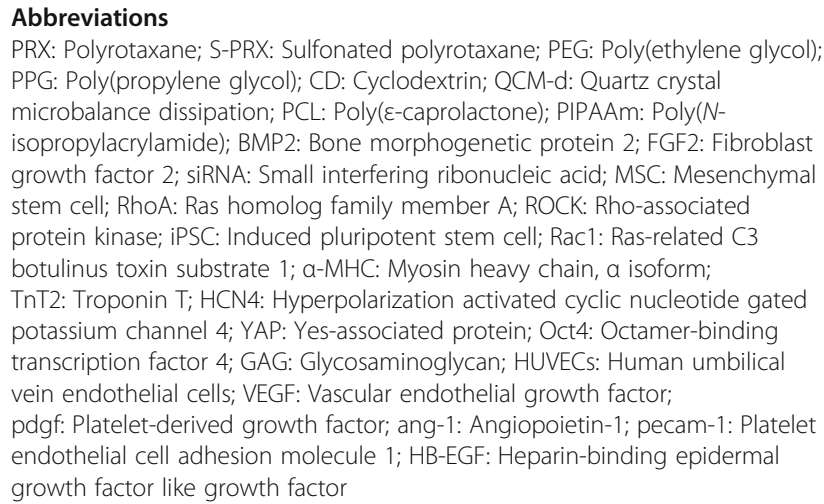
PPG: Poly(propylene glycol); CD: Cyclodextrin; QCM-d: Quartz crystal microbalance dissipation; PCL: Poly( $\varepsilon$-caprolactone); PIPAAm: Poly(Nisopropylacrylamide); BMP2: Bone morphogenetic protein 2; FGF2: Fibroblast growth factor 2; siRNA: Small interfering ribonucleic acid; MSC: Mesenchymal stem cell; RhoA: Ras homolog family member A; ROCK: Rho-associated protein kinase; iPSC: Induced pluripotent stem cell; Rac1: Ras-related C3 botulinus toxin substrate 1; a-MHC: Myosin heavy chain, a isoform;

TnT2: Troponin T; HCN4: Hyperpolarization activated cyclic nucleotide gated potassium channel 4; YAP: Yes-associated protein; Oct4: Octamer-binding transcription factor 4; GAG: Glycosaminoglycan; HUVECs: Human umbilical vein endothelial cells; VEGF: Vascular endothelial growth factor; pdgf: Platelet-derived growth factor; ang-1: Angiopoietin-1; pecam-1: Platelet endothelial cell adhesion molecule 1; HB-EGF: Heparin-binding epidermal growth factor like growth factor

Acknowledgements

None 


\section{Authors' contributions}

All authors contributed to the preparation of the manuscript. The authors read and approved the final manuscript.

\section{Funding}

This work was supported by the Grant-in-Aid for Scientific Research (A) from JSPS (No. 16H01852 to NY). AR and SI are supported by the Japan-India Science Cooperative Program (2017-2018) from the Japan Society for the Promotion of Science (JSPS). AR was supported by the Sasakawa Scientific Research Grant from The Japan Science Society (No. 2018-4056).

\section{Ethics approval and consent to participate}

Not applicable

\section{Consent for publication}

Not applicable

\section{Competing interests}

The authors declare that they have no competing interests.

\section{Author details}

'Section of Molecular Craniofacial Embryology, Graduate School of Medical and Dental Sciences, Tokyo Medical and Dental University, 1-5-45 Yushima, Bunkyo-ku, Tokyo 113-8549, Japan. ${ }^{2}$ Department of Organic Biomaterials, Institute of Biomaterials and Bioengineering, Tokyo Medical and Dental University, 2-3-10 Kanda-Surugadai, Chiyoda, Tokyo 101-0062, Japan.

\section{Received: 31 March 2020 Accepted: 7 August 2020}

\section{Published online: 11 November 2020}

\section{References}

1. Stratakis E. Novel biomaterials for tissue engineering 2018. Int J Mol Sci. 2018;19(12):3960

2. Christman KL. Biomaterials for tissue repair. Science. 2019:363(6425):340.

3. Wang JHC, Thampatty BP. An introductory review of cell mechanobiology. Biomech Model Mechanobiol. 2006;5(1):1-16.

4. Vogel V. Unraveling the mechanobiology of extracellular matrix. Annu Rev Physiol. 2018;80(1):353-87.

5. Ladoux B, Mège R-M. Mechanobiology of collective cell behaviours. Nat Rev Mol Cell Biol. 2017:18:743.

6. Engler AJ, Sen S, Sweeney HL, Discher DE. Matrix elasticity directs stem cell lineage specification. Cell. 2006;126(4):677-89.

7. Dalby MJ, Gadegaard N, Tare R, Andar A, Riehle MO, Herzyk P, et al. The control of human mesenchymal cell differentiation using nanoscale symmetry and disorder. Nat Mater. 2007;6:997.

8. Wang P-Y, Tsai W-B, Voelcker NH. Screening of rat mesenchymal stem cell behaviour on polydimethylsiloxane stiffness gradients. Acta Biomater. 2012; 8(2):519-30

9. Kim D-H, Provenzano PP, Smith CL, Levchenko A. Matrix nanotopography as a regulator of cell function. J Cell Biol. 2012;197(3):351.

10. Vogel V, Sheetz M. Local force and geometry sensing regulate cell functions. Nat Rev Mol Cell Biol. 2006;7:265.

11. Kohn Julie C, Zhou Dennis W, Bordeleau F, Zhou Allen L, Mason Brooke N, Mitchell Michael J, et al. Cooperative effects of matrix stiffness and fluid shear stress on endothelial cell behavior. Biophys J. 2015;108(3):471-8.

12. Berglin M, Andersson M, Sellborn A, Elwing $\mathrm{H}$. The effect of substrate molecular mobility on surface induced immune complement activation and blood plasma coagulation. Biomaterials. 2004:25(19):4581-90.

13. Kikuchi A, Okano T. Nanostructured designs of biomedical materials: applications of cell sheet engineering to functional regenerative tissues and organs. J Control Release. 2005;101(1):69-84.

14. Andersson $M$, Suska $F$, Johansson $A$, Berglin $M$, Emanuelsson $L$, Elwing $H$, et al. Effect of molecular mobility of polymeric implants on soft tissue reactions: an in vivo study in rats. J Biomed Mater Res A. 2008;84A(3):652-60.

15. Kidowaki M, Nakajima T, Araki J, Inomata A, Ishibashi H, Ito K. Novel liquid crystalline polyrotaxane with movable mesogenic side chains. Macromolecules. 2007:40(19):6859-62.

16. Takata T. Polyrotaxane and polyrotaxane network: supramolecular architectures based on the concept of dynamic covalent bond chemistry. Polymer Journal. 2006;38:1.
17. Harada A, Li J, Kamachi M, Kitagawa Y, Katsube Y. Structures of polyrotaxane models. Carbohydr Res. 1997:305(2):127-9.

18. Harada A, Li J, Kamachi M. Preparation and characterization of a polyrotaxane consisting of monodisperse poly(ethylene glycol) and acyclodextrins. J Am Chem Soc. 1994;116(8):3192-6.

19. Yui N, Katoono R, Yamashita A. Functional cyclodextrin polyrotaxanes for drug delivery. In: Wenz G, editor. Inclusion polymers. Berlin, Heidelberg: Springer Berlin Heidelberg; 2009. p. 115-73.

20. Tawa K, Kuboyama N, Ahmed SA, Tanaka M, Nakaoki T. Sensitive detection of a pseudo-polyrotaxane ultrathin film by SPR and QCM-D methods. Sens Actuators B. 2009;138(1):126-33.

21. Inoue $Y$, Ye L, Ishihara K, Yui N. Preparation and surface properties of polyrotaxane- containing tri-block copolymers as a design for dynamic biomaterials surfaces. Colloids Surf B Biointerfaces. 2012;89:223-7.

22. Bin Imran A, Esaki K, Gotoh H, Seki T, Ito K, Sakai Y, et al. Extremely stretchable thermosensitive hydrogels by introducing slide-ring polyrotaxane cross-linkers and ionic groups into the polymer network. Nat Commun. 2014:5:5124

23. Ooya T, Eguchi M, Yui N. Supramolecular design for multivalent interaction: maltose mobility along polyrotaxane enhanced binding with concanavalin A. J Am Chem Soc. 2003:125(43):13016-7.

24. Ooya T, Utsunomiya H, Eguchi M, Yui N. Rapid binding of concanavalin A and maltose-polyrotaxane conjugates due to mobile motion of a-cyclodextrins threaded onto a poly(ethylene glycol). Bioconjug Chem. 2005;16(1):62-9.

25. Ooya T, Yui N. Multivalent interactions between biotin-polyrotaxane conjugates and streptavidin as a model of new targeting for transporters. J Control Release. 2002;80(1):219-28.

26. Moon C, Kwon YM, Lee WK, Park YJ, Yang VC. In vitro assessment of a novel polyrotaxane-based drug delivery system integrated with a cell-penetrating peptide. J Control Release. 2007;124(1):43-50.

27. Huang F, Gibson HW. Polypseudorotaxanes and polyrotaxanes. Prog Polym Sci. 2005:30(10):982-1018.

28. Li JJ, Zhao F, Li J. Polyrotaxanes for applications in life science and biotechnology. Appl Microbiol Biotechnol. 2011;90(2):427-43.

29. Loethen S, Kim JM, Thompson DH. Biomedical applications of cyclodextrin based polyrotaxanes. Polymer Reviews. 2007;47(3):383-418.

30. Ohmori K, Abu Bin I, Seki T, Liu C, Mayumi K, Ito K, et al. Molecular weight dependency of polyrotaxane-cross-linked polymer gel extensibility. Chem Commun. 2016;52(95):13757-9.

31. Koyanagi K, Takashima Y, Yamaguchi H, Harada A. Movable cross-linked polymeric materials from bulk polymerization of reactive polyrotaxane cross-linker with acrylate monomers. Macromolecules. 2017;50(15):5695-700.

32. Nakahata M, Mori S, Takashima Y, Yamaguchi H, Harada A. Self-healing materials formed by cross-linked polyrotaxanes with reversible bonds. Chem. 2016;1(5):766-75

33. Fujita H, Ooya T, Kurisawa M, Mori H, Terano M, Yui N. Thermally switchable polyrotaxane as a model of stimuli-responsive supramolecules for nanoscale devices. Macromol Rapid Commun. 1996;17(8):509-15.

34. Ikeda T, Watabe N, Ooya T, Yui N. Study on the solution properties of thermo-responsive polyrotaxanes with different numbers of cyclic molecules. Macromolecular Chemistry and Physics. 2001;202(8):1338-44.

35. Tardy BL, Dam HH, Kamphuis MMJ, Richardson JJ, Caruso F. Self-assembled stimuli-responsive polyrotaxane core-shell particles. Biomacromolecules. 2014;15(1):53-9.

36. Ye L, Liu X, Ito K, Feng Z. The preparation of an azo-substituted polyrotaxane end-capped with PNIPPAAm and its dual stimuli-responsive behavior for drug delivery applications. J Mater Chem B. 2014;2(35):5746-57.

37. Seo J-H, Fushimi M, Matsui N, Takagaki T, Tagami J, Yui N. UV-cleavable polyrotaxane cross-linker for modulating mechanical strength of photocurable resin plastics. ACS Macro Lett. 2015:4(10):1154-7.

38. Seo J-H, Kakinoki S, Inoue Y, Yamaoka T, Ishihara K, Yui N. Inducing rapid cellular response on RGD-binding threaded macromolecular surfaces. J Am Chem Soc. 2013;135(15):5513-6.

39. Seo JH, Kakinoki S, Yamaoka T, Yui N. Movable polyrotaxane surfaces for modulating cellular adhesion via specific RGD-integrin binding. Adv Sci Tech. 2013;86:59-62.

40. Arisaka Y, Yui N. Polyrotaxane-based biointerfaces with dynamic biomaterial functions. J Mater Chem B. 2019:7(13):2123-9.

41. Schuldiner M, Yanuka O, Itskovitz-Eldor J, Melton DA, Benvenisty N. Effects of eight growth factors on the differentiation of cells derived from human embryonic stem cells. Proc Natl Acad Sci. 2000;97(21):11307. 
42. Xu Y, Shi Y, Ding S. A chemical approach to stem-cell biology and regenerative medicine. Nature. 2008;453:338.

43. Tay Y, Zhang J, Thomson AM, Lim B, Rigoutsos I. MicroRNAs to Nanog, Oct4 and Sox2 coding regions modulate embryonic stem cell differentiation. Nature. 2008:455:1124.

44. Sun Y, Chen CS, Fu J. Forcing stem cells to behave: a biophysical perspective of the cellular microenvironment. Annu Rev Biophys. 2012;41(1): 519-42.

45. Seo JH, Kakinoki S, Yamaoka T, Yui N. Directing stem cell differentiation by changing the molecular mobility of supramolecular surfaces. Adv Healthc Mater. 2015;4(2):215-22.

46. Seo J-H, Hirata M, Kakinoki S, Yamaoka T, Yui N. Dynamic polyrotaxanecoated surface for effective differentiation of mouse induced pluripotent stem cells into cardiomyocytes. RSC Adv. 2016;6(42):35668-76.

47. Rajendran AK, Arisaka Y, Iseki S, Yui N. Sulfonated polyrotaxane surfaces with basic fibroblast growth factor alters the osteogenic potential of human mesenchymal stem cells in short-term culture. ACS Biomaterials Science \& Engineering. 2019;5(11):5559-60.

48. Haugen HJ, Lyngstadaas SP, Rossi F, Perale G. Bone grafts: which is the idea biomaterial. J Clin Periodontol. 2019;46(Suppl 21):92-102.

49. Laurencin C, Khan Y, El-Amin SF. Bone graft substitutes. Expert Rev Med Devices. 2006;3(1):49-57.

50. Terauchi M, Ikeda G, Nishida K, Tamura A, Yamaguchi S, Harada K, et al. Supramolecular polyelectrolyte complexes of bone morphogenetic protein2 with sulfonated polyrotaxanes to induce enhanced osteogenic differentiation. Macromol Biosci. 2015;15(7):953-64.

51. Terauchi M, Inada T, Kanemaru T, Ikeda G, Tonegawa A, Nishida K, et al. Potentiating bioactivity of BMP-2 by polyelectrolyte complexation with sulfonated polyrotaxanes to induce rapid bone regeneration in a mouse calvarial defect. J Biomed Mater Res A. 2017;105(5):1355-63.

52. Arisaka $Y$, Yui N. Tethered bone morphogenetic protein-2 onto sulfonatedpolyrotaxane based surfaces promotes osteogenic differentiation of MC3T3E1 cells. J Biomater Sci Polym Ed. 2017;28(10-12):974-85.

53. Huey DJ, Hu JC, Athanasiou KA. Unlike Bone, Cartilage regeneration remains elusive. Science. 2012;338(6109):917.

54. Lee WK, Ichi T, Ooya T, Yamamoto T, Katoh M, Yui N. Novel poly(ethylene glycol) scaffolds crosslinked by hydrolyzable polyrotaxane for cartilage tissue engineering. J Biomed Mater Res A. 2003;67A(4):1087-92.

55. Ooya T, Ichi T, Furubayashi T, Katoh M, Yui N. Cationic hydrogels of PEG crosslinked by a hydrolyzable polyrotaxane for cartilage regeneration. React Funct Polym. 2007;67(11):1408-17.

56. Tachaboonyakiat W, Furubayashi T, Katoh M, Ooya T, Yui N. Novel biodegradable cholesterol-modified polyrotaxane hydrogels for cartilage regeneration. J Biomater Sci Polym Ed. 2004;15(11):1389-404.

57. Palecek SP, Loftus JC, Ginsberg MH, Lauffenburger DA, Horwitz AF. Integrinligand binding properties govern cell migration speed through cellsubstratum adhesiveness. Nature. 1997:385(6616):537-40.

58. Tran NQ, Joung YK, Lih E, Park KM, Park KD. RGD-conjugated in situ forming hydrogels as cell-adhesive injectable scaffolds. Macromolecular Research. 2011;19(3):300

59. Laschke MW, Harder Y, Amon M, Martin I, Farhadi J, Ring A, et al. Angiogenesis in tissue engineering: breathing life into constructed tissue substitutes. Tissue Eng. 2006;12(8):2093-104

60. Hyodo K, Arisaka Y, Yamaguchi S, Yoda T, Yui N. Stimulation of microvascular networks on sulfonated polyrotaxane surfaces with immobilized vascular endothelial growth factor. Macromol Biosci. 2019;0(0):1800346.

61. Arisaka $Y$, Yui N. Engineering molecularly mobile polyrotaxane surfaces with heparin-binding EGF-like growth factors for improving hepatocyte functions. J Biomed Mater Res A. 2019;107(5):1080-5.

62. Nam K, Seo JH, Kimura T, Yui N, Kishida A. Relationships between molecular mobility, fibrillogenesis of collagen molecules, and the inflammatory response: an experimental study in vitro and in vivo. J Colloid Interface Sci. 2014:433:16-25.

63. Kakinoki S, Seo JH, Inoue Y, Ishihara K, Yui N, Yamaoka T. Mobility of the Arg-Gly-Asp ligand on the outermost surface of biomaterials suppresses integrin-mediated mechanotransduction and subsequent cell functions. Acta Biomater. 2015;13:42-51.
64. Sekiya-Aoyama R, Arisaka Y, Yui N. Mobility tuning of polyrotaxane surfaces to stimulate myocyte differentiation. Macromol Biosci. 2020;20:1900424.

65. Lei X, Jia YG, Song W, Qi D, Jin J, Liu J, et al. Mechanical and optical properties of reinforced collagen membranes for corneal regeneration through polyrotaxane cross-linking. ACS Applied Bio Materials. 2019;2(9): 3861-9.

\section{Publisher's Note}

Springer Nature remains neutral with regard to jurisdictional claims in published maps and institutional affiliations.
Ready to submit your research? Choose BMC and benefit from:

- fast, convenient online submission

- thorough peer review by experienced researchers in your field

- rapid publication on acceptance

- support for research data, including large and complex data types

- gold Open Access which fosters wider collaboration and increased citations

- maximum visibility for your research: over $100 \mathrm{M}$ website views per year

At $\mathrm{BMC}$, research is always in progress.

Learn more biomedcentral.com/submissions 